\title{
"Cuando confluimos, influimos". Una aproximación a la idea de unidad en el activismo feminista contemporáneo
}

"When we converge, we influence." An approach to the idea of unity in contemporary feminist activism

\author{
Carmen Galdón Corbella \\ Investigadora Social \\ carmengaldon@yahoo.es (ESPAÑA)
}

Recibido: 16.11 .2020

Aceptado: 23.08 .2021

\section{RESUMEN}

"Cuando confluimos, influimos", fue una frase pronunciada por una veterana feminista. A partir de ella, este artículo explora la idea de unidad manejada en el activismo feminista testándola mediante una de las cuestiones que más controversia suscitan dentro de los movimientos sociales: la incidencia política sobre las instituciones. La aproximación a estas cuestiones se realiza mediante el estudio de la Marcha estatal contra las violencias machistas, que tuvo lugar el 7 de noviembre de 2015 — más conocida como $7 \mathrm{~N}$ - considerada un hito del feminismo reciente. Esta manifestación unitaria y masiva, que interpelaba directamente al Estado y a sus instituciones, la convierten en un campo de investigación privilegiado para profundizar sobre la cuestión planteada.

\section{PALABRAS CLAVE} $7 \mathrm{~N}$.

Movimiento feminista, incidencia política, violencia de género, Plataforma

\section{ABSTRACT}

«When we converge, we influence», was a phrase uttered by a veteran feminist. From there, this article explores the idea of unity in feminist activism, testing it through one of the most controversial issues within social movements: 
political advocacy on institutions. The approach to these issues is conducted on the study of The State March Against Machist Violence, better known as $7 \mathrm{~N}$, considered a milestone in recent feminism. This unitary and massive demonstration, which directly challenged the State and its institutions, makes it a privileged field of research to delve into the question posed.

\section{KEY WORDS}

Feminist movement, political advocacy, gender violence, machist violence, Platform 7N.

\section{INTRODUCCIÓN}

"Cuando confluimos, influimos" fue una frase pronunciada por una veterana feminista en referencia a una gran movilización en cuyo estudio se basa este artículo. Una sentencia destacable porque en tres palabras evoca temas centrales en el campo de los movimientos sociales como son la unidad y la incidencia social y política. Asimismo, al estar formulada desde un nosotras feminista, es decir, desde un claro sentimiento de pertenencia, invita a preguntase sobre cuestiones también de calado como son el impacto de estas acciones multitudinarias en la identidad, la volatilidad de dicha confluencia y sobre hasta qué punto esta puede ser manejada como sinónimo de unidad.

Las movilizaciones organizadas con vocación de ser masivas y unitarias como a la que alude la sentencia, se presentan como un campo privilegiado para investigar estas cuestiones, fundamentalmente porque la meta cumplida de una respuesta multitudinaria pone a prueba las expectativas en torno a las que se había construido la convocatoria. Aquí las actuaciones y valoraciones posteriores a la gran movilización tienen mucha importancia puesto que permiten indagar sobre hasta que punto los planteamientos acerca de para qué se quería confluir y sobre quién se pretendía influir eran suficientemente claros y compartidos.

Partiendo de estas reflexiones, en este artículo pretendo hacer una aproximación a la idea de unidad dentro del activismo feminista actual. Un tema cuasi ontológico que aterrizaré centrándome en el Estado español, en una movilización - la Marcha estatal contra las violencias machistas que tuvo lugar el 7 de noviembre de 2015, más conocida como $7 \mathrm{~N}$ - y en la perspectiva de las activistas que participaron en ella. El motivo de esta selección radica en que el $7 \mathrm{~N}$ es considerada por muchas feministas la primera gran manifestación unitaria del feminismo contemporáneo dentro del territorio español, convocada bajo la denominación única de "movimiento feminista", y porque en ella se planteó una interpelación al Estado y a sus instituciones explicitado como pocas veces en contextos de protesta masivos.

Estos tres aspectos del $7 \mathrm{~N}$-carácter multitudinario, vocación unitaria y su marcado enfoque de incidencia política- que desarrollaré posteriormente, re- 
sultan idóneos para explorar los límites del movimiento y, por tanto, la idea de unidad. Los dos primeros aluden a la ampliación y/o fortalecimiento de la base social, mientras que el tercero tiene que ver con la frontera, la que se establece entre el movimiento que interpela y quienes tienen el poder instituido para dar respuesta a las demandas, los interpelados. El cómo incidir —o más concretamente, el cómo pasar de la interpelación a una incidencia política que dé seguimiento a las reivindicaciones coreadas en una manifestación y plasmadas en un manifiesto- es una de las cuestiones que, como señalan algunos analistas y como comprobaremos en los testimonios, más controversia suscita dentro de los movimientos sociales y, por tanto, que más pueden poner en evidencia la naturaleza de esa unidad.

En síntesis, mi intención en este texto es abordar las preguntas que la sentencia "cuando confluimos, influimos" sugiere. Para ello exploraré la unidad dentro del activismo feminista contemporáneo a través de la incidencia política, con el convencimiento de que el poder tensionador y controvertido de esta última dentro de los movimientos sociales actuará a modo de prueba de esfuerzo sobre la primera proporcionando claves valiosas para su comprensión. Y esto lo haré poniendo el foco en el $7 \mathrm{~N}$, bajo la consideración de que sus peculiares características lo convierten en idóneo para este fin.

Los principales referentes teóricos en los que me basaré para centrar y profundizar en estas cuestiones, y que expondré más adelante, serán las ideas de unidad e identidad colectiva formuladas por Melucci, y para lo que compete a la incidencia, utilizaré algunos planteamientos sobre la dimensión política de los movimientos sociales señalados por Mcarthy, Smith y Zald, así como la definición y articulación de las agendas políticas definidas por Cobb, Robb y Robb ${ }^{1}$.

La hipótesis a la que modestamente pretendo apuntar en función de lo investigado hasta el momento y el limitado espacio que este texto me permite, es que la unidad entendida como la configuración homogénea y estable de un todo, en un movimiento social, por su propia naturaleza fundamentada en la acción y en la ampliación constante de sus bases, no es posible, no existe. Sin embargo, la unidad, en tanto que referente muy presente en el imaginario de todo movimiento, sí que podría decirse que existe, pero como idea, lo que la convierte en una suerte de ficción muy real. Esta importante presencia de la unidad como referente responde, sobre todo, a su enorme utilidad, principalmente respecto a dos aspectos que se retroalimentan mutuamente y determinantes para la supervivencia del movimiento: la conformación de una identidad colectiva, al ofrecerle agarraderas sobre las que pensarse frente a su realidad etérea (dentro); y la incidencia política, permitiendo proyectar una imagen visible para que sea tenido en cuenta (fuera). Es, en todo caso, una ficción de unidad que necesita para mantenerse de

\footnotetext{
1 Mi intención aquí no es hacer una revisión critica de los distintos enfoques y teorías que han abordado estos temas -cosa que escaparía a las dimensiones de este texto-, sino poner en evidencia aquellos que me han resultado de mayor utilidad en el análisis del material empírico de que dispongo. En todo caso, en lo que respecta a una rigurosa revisión y análisis teórico sobre las cuestiones de unidad e identidad véase el trabajo de Martínez (2019).
} 
su sucedáneo, esto es, de confluencias recurrentes y de las puestas en escena que estas ofrecen.

\section{Imagen 1: Lógica de interacción entre unidad y confluencia}

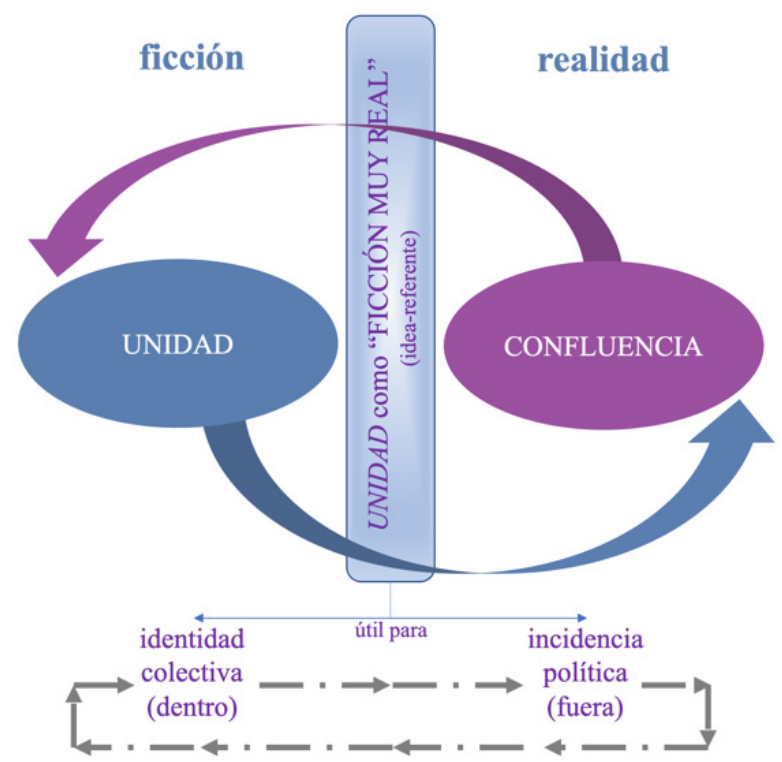

Fuente: elaboración propia

\section{EL DESBORDAMIENTO Y LAS NUEVAS LÓGICAS MOVILIZADORAS}

Reflexionar en torno a la unidad resulta de lo más pertinente en un contexto en el que el término "movimiento feminista" como categoría de análisis, muy ligado al de identidad colectiva, lleva tiempo siendo sometido a revisión. En esta labor encontrábamos a Gil (2011) que empleaba la denominación "nuevos feminismos" y la elocuente expresión de "sentidos comunes en la dispersión" para referirse a unas dinámicas que emergieron con fuerza en los años 90. Formas de hacer alejadas de las que Augustín (2003) describía en su análisis del que nombraba como "movimiento feminista español" entre los años 1975-1985, cuando la identidad colectiva parecía estar configurada en torno a organizaciones estructuradas y a un único sujeto político, la mujer; planteamientos no exentos de tensiones que auguraban lo que estaba por llegar. Más recientemente, Martínez (2019), a partir de una minuciosa revisión crítica de la conceptualización moderna de identidad y del análisis de trayectorias activistas, formula el concepto 
de "identidades en proceso", desde donde defiende que es más pertinente hablar de "movilizaciones feministas" que de "movimiento". Por su parte, Rovira, poniendo el foco en la penetración global y exponencial de las redes digitales de la última década, propone superar y dejar de estirar el concepto de movimiento social, ya sea "nuevo" o "novísimo", para adoptar el de "multitudes conectadas" que considera más acorde con la diversidad y apertura de sus lógicas identitarias. Resalta, además, el carácter feministizante de este fenómeno de digitalización conector de luchas sociales, en tanto que conlleva unos "modos de hacer y decir en red que cuestionan (...) el privilegio de lo masculino en todos los ámbitos de la construcción de significado del mundo occidental, la predominancia de líderes y las militancias estructuradas." (Rovira, 2018: 225-226).

Es en este escenario en el que las movilizaciones feministas de los últimos años han superado todas las previsiones. Bajo una lógica de código abierto y distribuido cada vez más inspirada en las redes digitales y facilitada por ellas, el feminismo ha ido permeando, traspasando una barrera que no hace mucho parecía infranqueable: la de las ya convencidas. Así, en estos años se han producido manifestaciones viralizadas, en donde la denuncia de las violencias machistas, en sus múltiples formas, ha tenido un enorme protagonismo. Hashtag como \#MiPrimerAsedio, \#MiPrimerAcoso, \#NiUnaMenos, \#VivasNosQueremos, \#MeToo, \#NoEsNo desde lugares mediáticos, pero también desde los más alejados de este foco, a los que se suman otras movilizaciones globalizadas como los paros/huelgas internacionales feministas de 2017, 2018 y 2019 con seguimiento masivo en la mayoría de los más de 170 países que llegaron a secundarla, o la perfomance "un violador en tu camino", creada y representada en Chile en 2019 por el colectivo Lastesis y replicada en todo el mundo, por poner dos ejemplos dispares.

Todas ellas son muestras de esta forma de hacer distribuida, heterodoxa y heterogénea. Brochazos que evidencian una retroalimentación y unas conexiones entre lo local y lo global y entre lo virtual y lo presencial muy eficaces en tanto que han conducido a una visibilidad del feminismo a escala planetaria y sin precedentes. Acciones que se inician atomizadas y efímeras, pero que, en virtud del contagio, la reiteración y el desborde conectan y arraigan. Así, si como ya señalara Melucci (1991), siempre ha sido necesario en la labor investigadora preguntarse sobre lo que subyace detrás de un movimiento social como "unidad empírica", en el contexto de la evolución del feminismo de la última década, esto cobra aun mayor relevancia. Tanto por el desbordamiento de lo que hasta entonces había sido una base social minoritaria y, aparentemente, bien definida, como por sus lógicas movilizadoras dirigidas, ya no a "unificar, sino en generar conexiones" para abordar un problema compartido (Gil, 2018: 21)².

2 En este sentido, la mirada situada desde Argentina pero globalizadora de Gago (2019) sobre las implicaciones del Paro Internacional de Mujeres de 2017 resulta muy reveladora de este enfoque. 


\section{MARCO TEÓRICO}

\subsection{Unidad: apariencia y utilidad}

Como punto de partida para el objetivo propuesto he asumido el planteamiento epistemológico de Melucci que considera la unidad como un dato empírico que debe ser explicado, siendo la tarea de quienes estudian los movimientos sociales "descubrir la pluralidad de elementos analíticos —orientaciones, significados y relaciones_- que convergen en el mismo fenómeno". Para Melucci el tratamiento de las acciones colectivas como "unificados actores empíricos" responde a la miopía de quién observa y que no mira más allá de manifestaciones visibles (Melucci, 1991: 357).

En el camino me he guiado también por sus ideas de unidad e identidad colectiva. Así, para Melucci la unidad debe ser tratada como un producto resultado de conjugar orientaciones diferentes y de la interacción de múltiples actores que se desenvuelven y toman decisiones en un contexto de oportunidades y restricciones. Los límites de la unidad así entendida no son precisos ni lineales al dibujarse a partir de interacciones, negociaciones e, incluso, de atribución de significados opuestos.

En coherencia con ello y desde un enfoque constructivista, para Melucci un "nosotras" nunca será algo completamente estable ni integrador, porque se construye mediante ajustes dinámicos que tienen que ver con como los actores sociales perciben los fines, los medios y el ambiente en el que tiene lugar la acción colectiva. Son los que denominan vectores y describe como interdependientes y sujetos a tensiones -internas y entre sí- constantes. Así pues, Melucci considera que el término "identidad colectiva" da cuenta de la necesidad de un nivel de identificación del actor colectivo, en donde la dimensión emocional y de construcción de significados juega un papel importante, pero que no refleja el carácter dinámico y procesual de su configuración (Melucci, 1991, 1994, 1999).

En un plano más concreto, Mueller (1994: 289), asumiendo la crítica del sociólogo italiano al tratamiento del movimiento de mujeres como un "todo unificado", observa la complejidad que subyace tras la imagen de uniformidad de grandes movilizaciones como la Huelga de Mujeres de 1970 en Estados Unidos, durante el Día de la Igualdad. Destaca, no obstante, lo determinante de la impresión de unidad transmitida (y retransmitida) para la configuración de lo que fue el inicio simbólico del movimiento de mujeres en dicho país, por mucho que este no fuera ni haya sido nunca ese todo unificado.

Esto alude, en definitiva, no ya a la construcción simplificadora de unidad por parte de quién investiga, sino a la que hacen otros actores sociales y al impacto que su reflejo tiene en el propio movimiento como un aspecto más a tener en cuenta en la configuración de un "nosotras", pero, también, como estrategia de incidencia. Muy ligado, todo ello, a una puesta en escena en donde los números cuentan, puesto que no es lo mismo la unidad de unas pocas personas, tendente a asociarse con marginalidad, que la de muchas, representación simbólica de una mayoría. Todo lo cual nos pone en el camino de la importancia de 
ahondar, además de en lo que oculta la apariencia de unidad, en la función que cumple, con una doble vertiente - podríamos decir, utilitaria — de construcción de una identidad colectiva, por un lado, y de incidencia política, por otro.

\subsection{De la unidad a la incidencia política}

En lo que compete a incidencia política, tomaré como punto de partida dos afirmaciones que McCarthy, Smith y Zald hacen en su análisis sobre la acción colectiva. La primera, enlazando con lo anterior, señala que la dificultad de acceso directo a los que denominan "decisores políticos", obliga a los movimientos sociales a recurrir a estrategias alternativas "para llamar la atención del público y de quienes diseñan las políticas que afectan a los problemas que desearían ser resueltos" (McCarthy et al., 1999: 413).

Trasladando esto, con el fin de facilitar el análisis, al lenguaje de las agendas políticas según las definen Cobb et al. (1976), cabría pensar que, ante la mencionada imposibilidad para influir directamente, lo que la apariencia de unidad de una convocatoria multitudinaria pretende es incidir sobre los diferentes entornos en los que estas se confeccionan. Es decir, primero colocar la cuestión en el imaginario colectivo para, a partir de ahí, incorporarla en la agenda pública, entendiendo como tal la compuesta por temas objeto de una amplia atención social y percibidos por un número considerable de población como necesitados de cambios, de los cuales responsabiliza a quienes detentan el poder formalmente instituido. La presión social resultante propiciaría entonces que el problema fuese incluido en otra agenda, la formal, a cargo de los mencionados poderes, que son los que cuentan con recursos públicos para revertir la situación o, al menos, actuar sobre ella ${ }^{3}$.

La segunda afirmación en la que deseo basarme, ya apuntada, señala que los significados que competen a la incidencia política son de los que más controversia suscitan dentro de los movimientos sociales (McCarthy et al.,1999). A esto debiera añadirse: especialmente la incidencia ejercida sobre las instituciones vinculadas al Estado. No solo por la carga polisémica de la noción de política, potenciada al unirse a incidencia, sino porque gran parte de la identidad de un movimiento social se construye en su diferencia y separación — pública y notoria - respecto a las instituciones. Será esta distancia la que avale una perspectiva no contaminada en relación con las cuestiones que denuncia, y la que lo legitime en su papel de una suerte de contrapoder sobre lo formalmente instituido. Son, pues, dos lógicas distantes y contrapuestas: la del movimiento, ubicada en aquello que podría ser y que adquiere su legitimidad mediante proyecciones de un futuro que imagina diferente (el otro mundo es posible o el sí se puede); y la de las instituciones, instalada en lo que ya existe, lo que está instituido y que

${ }^{3}$ McCarthy et al. (1999) diferencian entre cuatro agendas: mediática, pública, electoral y gubernamental. Sin embargo, la simplicidad de separación entre pública y formal propuesta por Cobb et al. (1976) considero que facilita y aporta claridad a este análisis. 
encuentra en la imagen de estabilidad que transmite un aval para su aceptación. La incidencia política realizada por un movimiento social sobre las instituciones supondría, en el plano simbólico, acortar esta distancia. Un acercamiento que, cabe prever, fácilmente suscite dudas, recelos y controversias internas.

Así pues, explorar las percepciones entre activistas que han participado en una gran movilización sobre incidencia política y, más concretamente, sobre la conveniencia y manera de pasar de la agenda pública a la formal, vendría a funcionar a modo de prueba de esfuerzo respecto a la unidad y la identidad colectiva, proporcionando claves valiosas sobre ambas.

\section{DISEÑO METODOLÓGICO}

El presente estudio surge en el contexto de uno más amplio sobre estrategias del activismo feminista para la incidencia iniciado en 2011 con mi tesis doctoral sobre feminismo y 15M. Esta se centró en la Acampada de la Puerta del Sol de Madrid y en la Comisión de Feminismos Sol, al tiempo que exploraba las percepciones de feministas de larga trayectoria sobre el 15M. La movilización del $7 \mathrm{~N}$ en 2015 y las huelgas feministas del 8 de marzo de 2018 y 2019 se presentaron como nuevas oportunidades para profundizar sobre la cuestión.

Para estas investigaciones, además del análisis de fuentes documentales diversas, realicé entrevistas semiestructuradas. Un total de 47 llevadas a cabo entre los años 2012 y 2018 a mujeres con edades comprendidas entre 19 y 67 años. Los criterios de selección y detalles de la muestra se resumen en la Tabla 1. 
Tabla 1: Criterios de selección de las muestras y fechas de los trabajos de campo

\begin{tabular}{|c|c|c|c|c|c|c|}
\hline $\begin{array}{l}\text { Pro- } \\
\text { testa }\end{array}$ & & Criterios de selección & & Edades & Trabajos de campo & \\
\hline \multirow{2}{*}{ 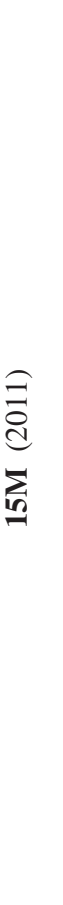 } & 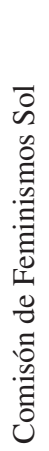 & $\begin{array}{l}\text { 1) Participación en el pro- } \\
\text { ceso de constitución de la } \\
\text { CFS. } \\
\text { 2) Presencia constante } \\
\text { (diaria o casi diaria) en la } \\
\text { Acampada de Sol hasta su } \\
\text { levantamiento. } \\
\text { 3) Continuidad como inte- } \\
\text { grante de la CFS durante el } \\
\text { proceso de descentralización } \\
\text { a las asambleas de barrios y } \\
\text { pueblos. }\end{array}$ & \multirow{4}{*}{ 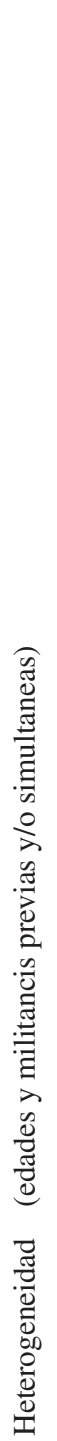 } & $\begin{array}{l}\text { Entre 25- } \\
63 \text { años }\end{array}$ & $\begin{array}{l}2012 \text { (junio-julio) } \\
2014 \text { (marzo-sept.) }\end{array}$ & 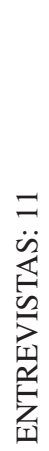 \\
\hline & 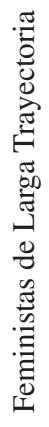 & $\begin{array}{l}\text { 1) Activismo feminista: mí- } \\
\text { nimo } 20 \text { años. } \\
\text { 2) Referente dentro del } \\
\text { feminismo en el Estado } \\
\text { español: publicaciones, } \\
\text { intervenciones públicas } \\
\text { (conferencia, docencia...en } \\
\text { torno a la teoría y/o práctica } \\
\text { feminista). } \\
\text { 3) Relación con el 15M: } \\
\text { cualquiera (participante, ob- } \\
\text { servadora, analista...). }\end{array}$ & & & $\begin{array}{l}2012 \text { (junio-sept.) } \\
2014 \text { (marzo-junio) }\end{array}$ & 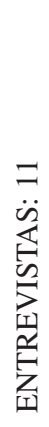 \\
\hline 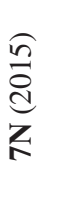 & & $\begin{array}{l}\text { Participación/implicación } \\
\text { continuada en el proceso de } \\
\text { organización. }\end{array}$ & & $\begin{array}{l}\text { Entre 24- } \\
67 \text { años }\end{array}$ & $\begin{array}{l}2017 \text { (junio-diciem- } \\
\text { bre) }\end{array}$ & 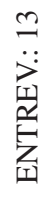 \\
\hline $\begin{array}{l}\underset{\partial}{\partial} \\
\vec{c} \\
\infty \\
\infty \\
\stackrel{d}{d} \\
\sum_{\infty}\end{array}$ & & $\begin{array}{l}\text { Participación/implicación } \\
\text { continuada en el proceso de } \\
\text { organización de la huelga y } \\
\text { manifestación. }\end{array}$ & & $\begin{array}{l}\text { Entre 19- } \\
67 \text { años }\end{array}$ & 2018 (febrero-junio) & 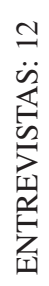 \\
\hline
\end{tabular}

Fuente: elaboración propia 
Durante el análisis de las entrevistas emergieron algunos temas, vinculados al principal, con entidad suficiente como para ameritar un estudio específico. Este fue el caso de las diferentes orientaciones sobre incidencia política y su relación con la unidad. El conjunto de los tres episodios de protesta permitió valorar la relevancia de la cuestión y una visión global, sin embargo, el 7N, por sus peculiares características ya señaladas, se presentaba como el más idóneo para focalizar el estudio.

El guion de la entrevista sobre el $7 \mathrm{~N}$ contenía veinte preguntas distribuidas en cuatro bloques temáticos (valoración general y vinculación con el 7N; el relato y las terminologías; participación, apoyos y resistencias; perspectivas de futuro) y se aplicó a una muestra de trece feministas implicadas activamente en su organización. Todas pertenecían en el momento en que fueron entrevistadas a colectivos específicamente feministas (11) o de sensibilidad feminista (2). La mayoría estaban, asimismo, participando simultáneamente en plataformas (9) y en más de un colectivo (9). Dos pertenecían a sindicatos y una a una plataforma municipalista y a un partido político, si bien son ocho las que declararon haber estado en el pasado vinculadas a algún partido político (3), sindicato (4) o ambos (1).

El trabajo de campo se llevó a cabo entre los meses de junio y diciembre de 2017 (Tabla 1), esto es, transcurrido un año y medio desde la movilización, un margen que facilitaba reflexiones con perspectiva, importante de cara a explorar las expectativas y el recorrido de las agendas políticas.

La muestra estuvo distribuida en nueve territorios heterogéneos en cuanto a tamaño y características, con una mayor representación de las localidades de Valencia, donde surgió la iniciativa, y Madrid, donde se llevó a cabo la Marcha (Tabla 2).

Tabla 2: Distribución de entrevistadas por lugar de residencia

\begin{tabular}{cc}
\hline Número de entrevistadas & Localidades \\
\hline 1 & Alcázar de San Juan-Ciudad Real \\
\hline 1 & Barcelona \\
\hline 1 & Fuerteventura \\
\hline 1 & León y Santovenia de la Valdoncina ${ }^{4}$ \\
\hline 4 & Madrid \\
\hline 2 & Santiago de Compostela \\
\hline 1 & Tenerife \\
\hline 13 entrevistadas & Valencia \\
\hline
\end{tabular}

Fuente: elaboración propia

${ }^{4}$ La entrevistada vivía entre León ciudad y Santovenia de la Valdoncina, un pueblo próximo a la primera. 


\section{LA MARCHA ESTATAL CONTRA LAS VIOLENCIAS MACHISTAS}

\subsection{Antecedentes}

La Marcha estatal contra las violencias machistas es considerada por muchas activistas la primera gran manifestación unitaria del movimiento feminista en el Estado español y, como tal, un hito del feminismo contemporáneo. Surge en un contexto abonado en el que los antecedentes de la Primavera Árabe en 2011 y el ciclo de protestas simultáneas y encadenadas, así como lo generado en torno suyo por todo el mundo, no le son ajenos.

En el Estado español esa primavera tuvo nombre propio: 15M. A sus acampadas acudieron feministas atraídas por el ambiente de inclusividad y apertura que parecía respirarse en las plazas. Estas mujeres, jóvenes muchas de ellas, se organizaron dentro del movimiento mixto en comisiones feministas. Se mezclaron con el conjunto en las acampadas y luego, una vez levantadas estas, en las asambleas de barrios y pueblos donde se descentralizó el 15M, contribuyendo, a pesar de las resistencias, a normalizar el feminismo y su presencia ${ }^{5}$.

El ambiente en las calles que reclamaba cambios en un principio no tuvo reflejo en las urnas ni en la política institucional. Así, el 20 de noviembre de 2011, el Partido Popular ganó las elecciones, sustituyendo al Partido Socialista en el gobierno en continuidad con la política de alternancia de estas dos grandes formaciones. En su agenda, una reaccionaria reforma de la Ley del aborto que provocó un ciclo de protestas feministas con un marcado componente intergeneracional. Tres años de continuas movilizaciones cuyo momento álgido tuvo lugar el 1 de febrero de 2014 con El tren de la libertad, una protesta masiva impulsada desde dos organizaciones asturianas, con una importante implicación de feministas del PSOE y de los sindicatos mayoritarios. Finalmente el anteproyecto de ley fue retirado y el ministro Gallardón, abanderado de su defensa, dimitió.

En el proceso, el movimiento feminista se fue cargando de energía y visibilidad: las plataformas cobraban fuerza en sus territorios y se manifestaban tras cada asesinato machista. En Madrid, uno de los escaparates más mediáticos, el 8 de marzo de 2014, Día Internacional de las Mujeres, se produjo una manifestación masiva como nunca se había visto en esa fecha. En todo ello, las fórmulas abiertas y distribuidas traídas por las feministas del 15M jugaron un importante papel ${ }^{6}$.

Es en este contexto en el que en 2015, un grupo de mujeres en su mayoría pertenecientes a plataformas y organizaciones feministas de distintos territorios, se reúne en Madrid. Su intención: organizar una gran movilización unitaria y estatal para exigir medidas específicas y urgentes que aborden las violencias machistas de manera integral y como una cuestión de Estado.

\footnotetext{
5 Un análisis de estas resistencias puede consultarse en Galdón (2018a)

6 Para ampliar sobre este tema véase Galdón (2018b)
} 


\subsection{Características}

El $7 \mathrm{~N}$ fue una marcha estatal y unitaria. Estatal porque, aunque fuera de manera desigual, consiguió una amplia participación de territorios mediante un cuidado trabajo de inclusividad y respeto por la diversidad organizativa y lingüística.

Respecto a su vocación unitaria, lo más representativo y simbólico fue una marea morada y violeta, los colores del feminismo, marchando detrás de una gran pancarta que rezaba "movimiento feminista", así como un manifiesto que empezaba y terminaba con esta denominación colectiva. En el proceso de organización participaron, sobre todo, asociaciones y plataformas territoriales que tuvieron clara la idea de hacer visible al movimiento por encima de cualquier sigla.

\section{Imagen 2: Cabecera de la Marcha. Agencia EFE}

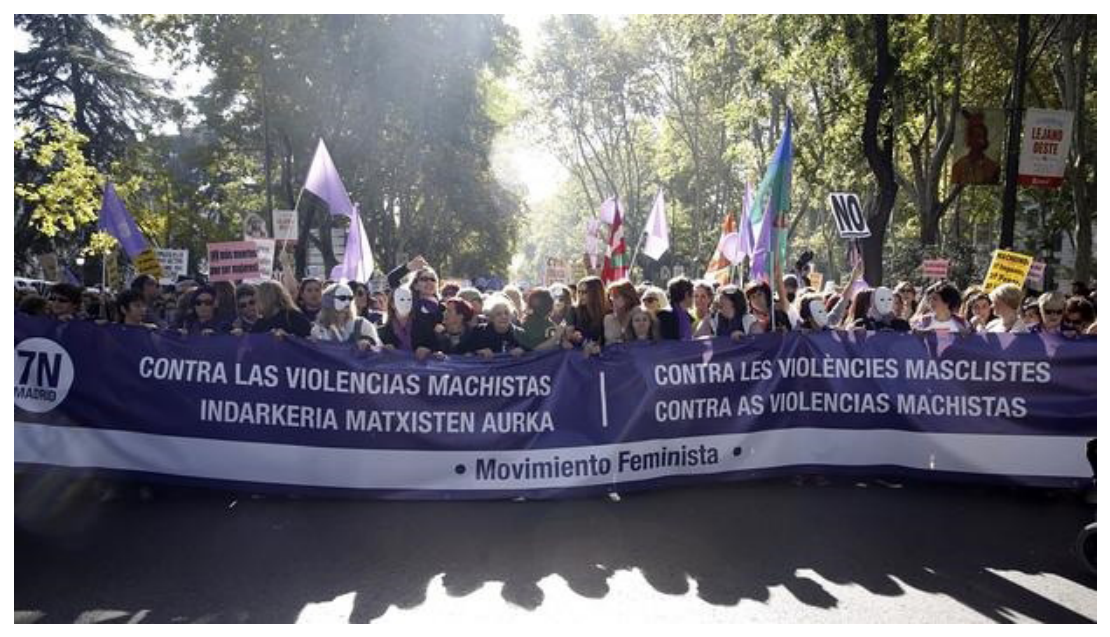

A los partidos políticos, sindicatos y administraciones se les pedía, por un lado, apoyo y, por otro, que fueran detrás de la cabecera de la manifestación la cual - se les explicaba - estaría reservada al movimiento feminista. Dichos apoyos se hicieron públicos en la web de la Marcha, en total 222, al igual que los 322 colectivos convocantes ${ }^{7}$. En definitiva, fue una confluencia conseguida bajo la lógica de hacerla compatible con la diversidad.

En cuanto a la incidencia política, el manifiesto contenía una interpelación explícita al Estado y a sus instituciones, así como al gobierno y sus políticas, al

${ }^{7}$ Listado de entidades en: http://www.forumpoliticafeminista.org/?q=las-organizaciones-feministas-ante-el-cambio-generacional-y-pol\%C3\%ADtico-2011-2016-0 
tiempo que utilizaba conceptos que aludían a lugares comunes del imaginario colectivo $^{8}$ :

1. "Terrorismo machista": evocaba, sin nombrarlo, el precedente de la lucha antiterrorista en el Estado español. Se ponía en evidencia, así, el agravio comparativo que suponía que, en la lucha contra la banda terrorista ETA, con 829 asesinatos en su haber desde 1960, el Estado pusiera todos los medios para erradicar la violencia y reparar a las víctimas, frente a la inacción en el caso de las 1378 mujeres asesinadas desde 1995 hasta aquel momento.

2. "Violencias machistas" en lugar de "violencia de género" que la ley 1/2004 en vigor utiliza ${ }^{9}$. La intención era superar el sentido restringido de dicha norma que circunscribe esta violencia al ámbito de la pareja o expareja. Se aludía a dos referentes internacionales que avalaban la petición: la Convención sobre la Eliminación de toda forma de Discriminación contra la Mujer, de Naciones Unidas (CEDAW) y el Convenio de Estambul del Consejo de Europa, ambos ratificadas por España en 1983 y 2014 respectivamente.

3. "Cuestión de Estado": la voluntad era distanciarse del más común "Pacto de Estado". Se buscaba trasmitir la necesidad de una política de Estado sostenible, por encima de pactos coyunturales o partidistas. Se trataba, como rezaba el manifiesto, de que "toda la sociedad y sus organizaciones e instituciones se comprometan en esta lucha."

La inclusión de estos conceptos en el manifiesto se hizo por consenso. Al mismo se llegó mediante largos debates que permitieron los casi nueve meses de preparación del 7N. Unos contenidos que marcaban explícitamente, como pocas veces, hacia dónde debía dirigirse la incidencia.

\subsection{Después del $7 \mathrm{~N}$ ¿qué? De la interpelación masiva y unitaria a la incidencia política}

El 7 de noviembre de 2015, mujeres procedentes de todos los rincones de la geografía española tiñeron de morado y violeta el centro de Madrid. Los medios se hicieron eco, llegando a calificar la movilización de histórica (Borraz \& Domenech, 2015; La Sexta, 2015, entre otros).

\footnotetext{
${ }^{8}$ Manifiesto completo disponible en: https://plataforma7n.files.wordpress.com/2017/01/manifiesto-7n-07-11-15-544-firmas-1.pdf

${ }^{9}$ Ley de Medidas de Protección Integral contra la Violencia de Género. Disponible en: https:// www.boe.es/buscar/pdf/2004/BOE-A-2004-21760-consolidado.pdf
} 


\section{Imagen 3: Calle Gran Vía durante el 7N. Foto propia.}

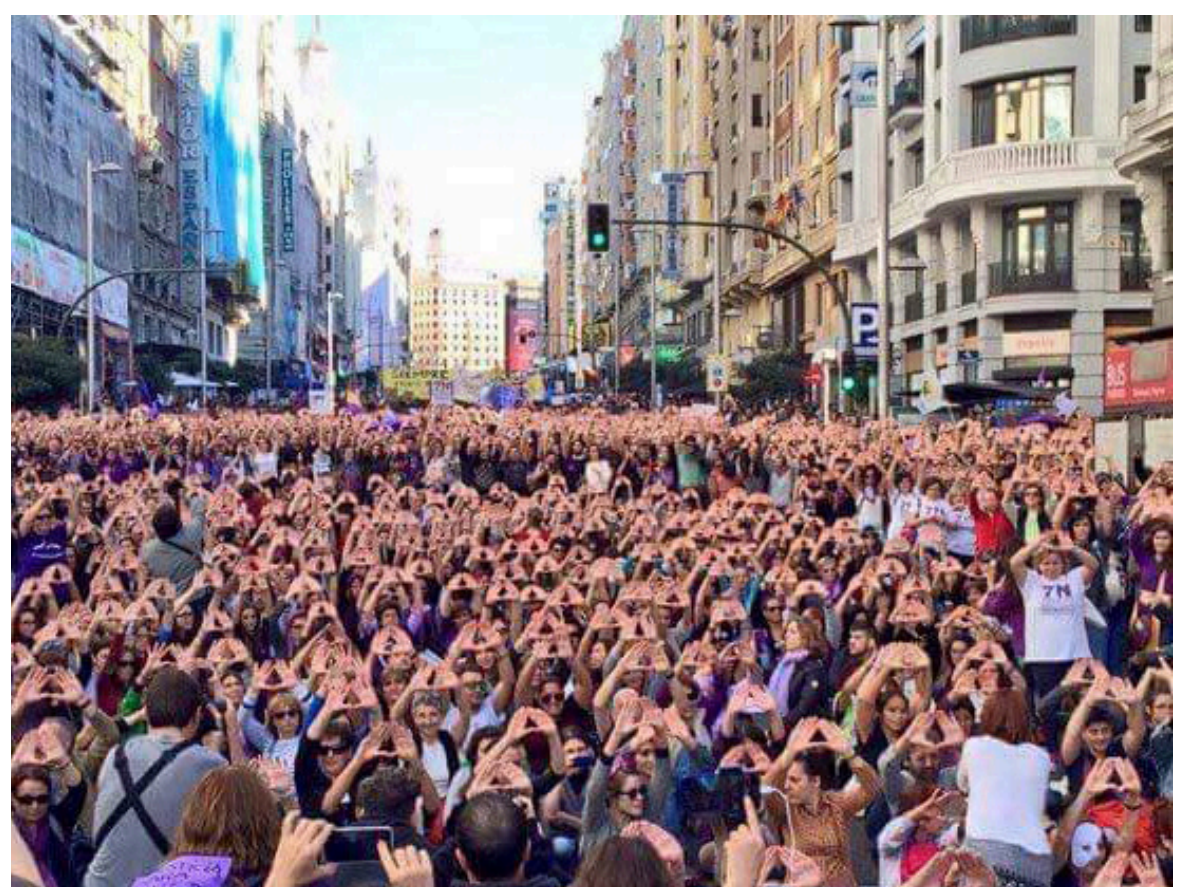

Tras la misma se produjeron dos circunstancias que, si no totalmente, en gran parte pueden ser atribuibles al impacto de la movilización y su proceso organizativo $^{10}$.

1. Constitución de la Plataforma $7 \mathrm{~N}$ :

El 30 de enero de 2016, en una reunión de evaluación de la Marcha, se constituyó la denominada "7N, Plataforma feminista contra las violencias machistas" como estructura permanente por parte de algunas de las entidades participantes. En su resolución de constitución catalogaban la Marcha de hito por tres razones: unidad, capacidad de movilización y repercusión social. Señalaban que, a pesar de este éxito, los objetivos seguían pendientes, resaltando la necesidad de que las violencias machistas se convirtieran en una "cuestión de Estado". Asimismo, declaraban su voluntad de actuar como interlocutoras con "los poderes públicos,

${ }^{10}$ Nunca es fácil establecer causalidades acerca del impacto de un movimiento social. No obstante, aquí hay elementos que apuntan a ellas en tanto que se cumplen los requisitos que señala Aguilar (2019) para ello. Esto es, existen resultados que pueden ser vinculados con demandas explícitas y con las acciones realizadas para intentar conseguirlas. 
instituciones, medios de comunicación y demás agentes sociales" y de apoyar las iniciativas feministas de los diferentes territorios ${ }^{11}$.

Fue una decisión no exenta de polémica que no todos los colectivos organizadores de la Marcha apoyaron y de las que se fueron descolgando algunos de los que inicialmente la secundaron. Ello hace de esta circunstancia una oportunidad para explorar la volatilidad de la confluencia en el marco de una manifestación unitaria, ahondar en los posicionamientos en torno a la incidencia política institucional, así como sobre la legitimidad y representatividad de este tipo de estructuras surgidas al calor de una gran movilización.

2. Pacto de Estado:

El 15 de noviembre de 2016, un año después de la Marcha, el Congreso de los Diputados aprobó por unanimidad una Proposición no de Ley que reclamaba un Pacto de Estado contra la violencia de género. Para ello proponía poner en funcionamiento una Subcomisión dentro de la Comisión de Igualdad con el fin de articularlo. Un acuerdo para vincular "a todos los partidos políticos, poderes del Estado y sociedad civil en un compromiso firme en pro de una política sostenida para la erradicación de la violencia de género." Al efecto se establecieron cuatro meses de plazo para elaborar un informe con medidas específicas para erradicar "las diferentes formas de violencia de género", haciendo alusión expresa al Convenio de Estambul y a la CEDAW, y dos meses para que, una vez aprobado el informe y remitido al Gobierno, este lo sometiera "a acuerdo con los representantes de Comunidades Autónomas, Ayuntamientos, partidos políticos, administración de Justicia y asociaciones sindicales, empresariales y asociaciones civiles"12. La Plataforma 7N fue una de las entidades llamadas a consulta. Finalmente, tras tres prorrogas, el 28 de septiembre de 2017, el Congreso aprobó un Pacto de Estado con 214 medidas y un presupuesto de 1.000 millones de euros a ejecutar en cinco años ${ }^{13}$.

Esta sucesión de acontecimientos en el ámbito institucional directamente vinculados a lo demandado añade interés a este caso cuyo trabajo de campo, recordémoslo, se desarrolló durante o inmediatamente después de la aprobación del Pacto de Estado.

${ }^{11}$ Resolución disponible en: https://observatorioviolencia.org/7n-plataforma-feminista-contra-las-violencias-machistas/

12 Nota de prensa del Congreso disponible en:

http://www.congreso.es/portal/page/portal/Congreso/Congreso/SalaPrensa/NotPre?_pir ef73_7706063_73_1337373_1337373.next_page=/wc/

${ }_{13}^{13}$ En este punto llamar la atención sobre los reiterados incumplimientos del Pacto denunciados por la Plataforma $7 \mathrm{~N}$ en su labor de seguimiento. Disponible en: https://plataforma7n.wordpress.com/category/notas-de-prensa/ 


\section{EL 7N DESDE UNA PERSPECTIVA ACTIVISTA}

Este epígrafe incluye una reconstrucción del $7 \mathrm{~N}$, desde el proceso de preparación de la Marcha hasta la aprobación del Pacto de Estado, principalmente a través de los testimonios de las entrevistadas para un mejor acercamiento a sus percepciones sobre los temas objeto de estudio.

\subsection{Origen y organización}

La iniciativa de una marcha estatal fue lanzada en las redes sociales por una conocida feminista y sindicalista de Valencia que, tras comprobar su buena acogida, trasladó la propuesta a la coordinadora feminista del territorio. Hay práctica unanimidad entre las entrevistadas en considerar que el origen y la forma de canalizar la propuesta fue determinante, poniendo el acento en la confianza que suscitaba la persona que la lanzó y/o en que, al provenir de Valencia, las reticencias sobre las connotaciones centralistas de una Marcha en la capital, en cierta medida, se minimizaban. Así mismo, todos los testimonios coinciden en señalar la dureza del momento respecto a la violencia contra las mujeres y la falta de respuesta del Estado como elementos clave.

Sobre estas bases no tardó en imponerse la idea de que era necesaria una reunión que finalmente se llevó a cabo el 28 de febrero de 2015 en Madrid. Aquí se tomó la decisión de organizar una gran movilización estatal en la capital el 7 noviembre, casi nueve meses más tarde. El acuerdo sobre la localización, por mucho que se valorara positivo en términos logísticos y de proximidad con las instituciones, suscitó reticencias, al tiempo que se considera que determinó algunas ausencias de territorios donde el nacionalismo está más presente:

...aquí en Cataluña, claro, fue motivo para que muchas mujeres que luchan contra las violencias no vinieran, el hecho de que se hiciera en Madrid, por un tema de centralidad política (E7, Barcelona, 08/2017). ${ }^{14}$

Los testimonios indican la importancia de las redes sociales digitales para que la iniciativa prosperara, valorando, además, que con ellas se suple la falta de recursos de un feminismo autónomo/independiente, al tiempo que facilita que poblaciones más aisladas se sientan parte:

Leía todo lo que llegaba, participaba en las redes (...) y me sentí parte de un todo, que a veces es lo que a mí me ha ocurrido aquí en las islas Canarias, la necesidad de formar parte de una globalidad (E11, Fuerteventura, 10/2017).

Pero paralelamente resaltan lo determinante de las distancias cortas, de lo presencial, para que la confianza terminara de afianzarse: “...que esa compañera

${ }^{14}$ Donde la letra "E" seguida de número (E1...E13) identifica a cada entrevistada, seguida del lugar de residencia y del mes/año en que se realizó la entrevista. 
fuera a esa reunión también te da la tranquilidad de que, bueno, vale, esto que percibimos vía las redes, efectivamente es asî” (E3, Santiago, 07/2017).

El margen de casi nueve meses para organizar la Marcha se consideró, asimismo, fundamental. Permitió que la idea fuera tomando forma mediante las aportaciones de quienes se iban incorporando al proceso. Se coincide también en la importancia de las cuatro asambleas generales que tuvieron lugar en Madrid, a las que acudieron, al menos en una ocasión, representantes de un total de 105 organizaciones y plataformas ${ }^{15}$, así como en lo determinante que fue la manera abierta y transparente de funcionar de la lista de correo: "había mucha transparencia de colgar las actas. De cualquier cosa que tuviéramos un problema: bueno y ¿qué pasa con...? y tropecientos mensajes." (E2, Madrid, 07/2017)

En general, las entrevistadas catalogan el $7 \mathrm{~N}$ como un éxito que atribuyen básicamente a:

1. La voluntad de inclusión en donde se reconoce el papel de las plataformas contra la violencia que en los distintos territorios llevaban tiempo trabajando y el acierto del 7N al haber sabido involucrarlas.

2. La voluntad de mantenerse al margen de sectarismos y partidismos, teniendo claro que la participación de feministas con doble militancia -dentro de partidos políticos o sindicatos - era también importante.

3. La horizontalidad, conjugada con reconocimientos a liderazgos individuales: "no hubo un liderazgo tan potente que borrara al colectivo" (E4, Santiago, 07/2017).

4. La posibilidad que ofreció un proceso largo para facilitar nuevas incorporaciones y para llegar a lugares comunes sin precipitar los consensos: "no fue organizar solo una manifestación, sino que fue organizar las cabezas feministas, miles de reconceptualizaciones, de debates superinteresantes." (E1, Madrid, 06/2017).

\subsection{Del valor de la unidad a la inercia de la dispersión}

La unidad se maneja entre las entrevistadas como un valor sin paliativos y estratégico: "es muy importante generar unidad, y dar visión unitaria. Decir, somos muchas y actuamos en bloque" (E13, León, 12/2017).

La recompensa, ser vistas y reconocidas: "la manifestación fue: ¡ostras, que sí, que sí, que la gente nos quiere! (...) que la gente lo está viendo" (E12, Alcázar, 10/2017); y ser consideradas por un poder que parecía indiferente: "la fuerza del movimiento feminista pone en la agenda política a la agenda feminista" (E6, Madrid, 08/2017).

15 Detalle en: http://www.forumpoliticafeminista.org/?q=las-organizaciones-feministas-ante-el-cambio-generacional-y-pol\%C3\%ADtico-2011-2016-0 
Los testimonios también reflejan la emoción de quienes participan en una movilización multitudinaria, unidas, el sentimiento de comunión, de haber formado parte de un momento único, de haber hecho historia:

...eclosión de fuerza y de entusiasmo. ¡De subidón! ¡uau! (...) Hicimos lo que teníamos que hacer (E4, Santiago, 07/2017).

Esta manifestación pasará a la historia, cuando estemos muertas nosotras estoy convencida de que el feminismo la reivindicará (E5, Madrid, 08/2017).

Fue la primera manifestación unitaria del movimiento feminista, que creo que marcó un hito en la historia (E9, Valencia, 09/2019).

Una emoción que ensambla lo personal con lo colectivo reactivando la cohesión y la conciencia de movimiento:

"Exultante de ver todo aquello, de vernos" (E4, Santiago, 07/2017).

"Todo el mundo se quería, la gente se abrazaba" (E11, Fuerteventura, 10/2017).

"Yo por eso me siento también en lo personal muy unida a muchas mujeres, porque haber vivido algo así es que no se te olvida nunca en la vida" (E6, Madrid, 08/2017).

La unidad se muestra como un referente, algo por lo que merece la pena dejar aparcadas cuestiones que en otros escenarios se considerarían irrenunciables: "vamos a buscar las cosas que nos unan y lo que separe, no lo tengamos en cuenta" (E8, Valencia, 09/2017). Una idea de unidad alejada de toda uniformidad, conjugada con la de diferencia y construida a partir del reconocimiento de que el feminismo es diverso, consciente de las dificultades que ello supone: “...no hay un único feminismo (...), es muy diverso (...) creo que el poder reconocer eso posibilitó que fuera una manifestación en la que estábamos todas" (E8, Valencia, 09/2017).

La configuración de un marco abierto y flexible para el entendimiento jugó un papel importante en esto: "se creó un marco tan amplio que dio opción a que mucha gente nos pudiéramos sentir identificadas con el objetivo" (E10, Tenerife, 10/2017). Ello compaginado con una clara conciencia de la fragilidad y lo efímero de la unión, de que esta es posible mediante un ejercicio de contención por el que no se tocan cuestiones sobre las que existen posturas enfrentadas, como son la de la prostitución o el sujeto político del feminismo ${ }^{16}$. El resultado, un equilibrio inestable en donde el miedo a la ruptura está muy presente y el conflicto se tiende a considerar latente, incluso en los momentos de mayor confluencia:

16 Cuestiones que no podemos desarrollar aquí porque supondría alejarnos de nuestro objetivo, pero sí es importante tener en cuenta como telón de fondo. 
...yo creo que eso se gestionó bastante bien. Sigue siendo un conflicto, porque yo creo que esto es un conflicto que nunca se va a resolver como muchos otros conflictos que lo único que podemos hacer es como los vamos colocando en cada una de las situaciones que vamos viviendo. (E1, Madrid, 06/2017)

En este sentido, justamente la entrevistada que pronunciaba las palabras "cuando confluimos, influimos" que han dado origen a este artículo, señala una tendencia a la dispersión que considera caracteriza al movimiento:

...otra lección aprendida, que la pervivencia de ciertos hábitos sectarios en el movimiento feminista no permitieron una continuidad de esos modelos de coordinación, sino que, después, se fueron dispersando. (...). Y otra enseñanza: que cuando hemos hecho algo para superar la dispersión, hemos influido (E10, Tenerife, 10/2017).

\subsection{Elementos que tensionan la unidad. "Lo institucional"}

Los discursos de las entrevistadas a menudo aparecen atravesados por una suerte de tensión dentro-fuera, en donde el posicionamiento con respecto a las instituciones juega un papel fundamental. Una tensión de fronteras graduables, confusas, difusas, difíciles de delimitar y que orienta muchas de sus reflexiones, a partir de las cuales es posible identificar algunos elementos que podrían tener parte de responsabilidad en la tendencia a la dispersión mencionada en el epígrafe anterior como característica del movimiento.

Así, es frecuente que se hable de "lo institucional" sin grandes precisiones, como un todo frente al cual se define al movimiento. Sin embargo, cuando se alude a instituciones concretas, sí se observan distinciones, organizadas en función de la distancia simbólica que se establece con respecto a ellas. Un distanciamiento que se gradúa de mayor a menor según se trate de instituciones vinculadas al Estado y al Gobierno, partidos políticos, sindicatos, organizaciones sociales u organizaciones feministas. Esta distancia, a su vez, continúa ajustándose en el cruce con otras variables, por ejemplo, según dónde se ubique la institución dentro del arco ideológico derecha-izquierda; o en el caso de los sindicatos, en función de si son mayoritarios o minoritarios; y en el de las organizaciones sociales y las feministas, si tienen o se sospecha que tengan vinculaciones partidistas o institucionales o, por el contrario, si se identifican con un activismo de base o autónomo. Y es en este juego de intersecciones y de ajustes de distancias que, en cierto momento, parece perderse la perspectiva, y los límites se desdibujan. Este es el caso de los partidos políticos y sindicatos, con feministas en su seno - la llamada doble militancia- objeto de muchas reflexiones.

Otras de las cuestiones recurrentes que también ofrecen pistas sobre la dificultad para establecer límites son, por un lado, la falta de recursos de un feminismo que se pretende autónomo/independiente y, por otro, los reconocimientos y apoyos institucionales. Ambas muestran una tensión muy presente entre utilizar 
o demandar a las instituciones - ya sea porque se conciba como un derecho, ya sea porque se conciba como una necesidad- y el miedo a ser fagocitadas por ellas. Abordaré cada una de las tres cuestiones por separado:

1. Doble militancia:

Algunas entrevistadas catalogan a las instituciones como estructuras patriarcales, situándolas en las antípodas del feminismo: "[el movimiento feminista] no tiene vocación de generar una estructura tradicional patriarcal, como un sindicato o un partido." (E1, Madrid, 06/2017). Una distancia que también establecen feministas que han estado dentro de esas estructuras y las conocen bien: "desterrar formas de trabajar como los partidos políticos. Y yo lo digo porque vengo de esa escuela, y lo sé" (E4, Santiago, 07/2019). El planteamiento generalizado, no obstante, es que los partidos y sindicatos son aliados necesarios: "porque solamente el movimiento feminista no podemos lograr un cambio" (E8, Valencia, 09/2017). Al efecto, debe destacarse que la iniciativa de la Macha fue lanzada por una sindicalista que desde el principio tuvo claro que el papel de los sindicatos y partidos era estar detrás, dejando todo el protagonismo a las mujeres $\mathrm{y}$ al feminismo de base.

En todo caso, las entrevistadas pertenecientes a estas instituciones parecen tener también claras las prioridades: "las mujeres que estamos en los partidos tenemos que hacer presión desde dentro con lo que el movimiento feminista nos dice" (E8, Valencia, 09/2017); "si tú estás en un espacio de movimientos sociales, tienes que tener claro que formas parte del movimiento social" (E4, Santiago, 07/2017).

Sin embargo, algunos testimonios señalan unos límites confusos y la necesidad de estar clarificándolos constantemente:

Dentro de la Plataforma 7N había gente afín al PSOE y gente afín a Podemos, entonces estábamos todo ese tiempo con los típicos rumores: es que la Plataforma $7 \mathrm{~N}$ está en manos de Podemos, es que la Plataforma $7 \mathrm{~N}$ está en manos del PSOE iy venga, y dale, y vuelta con eso! (E5, Madrid, 08/2017).

...vi en las reuniones estatales que venía gente de partidos, y eso no me pareció. Yo considero que deberían haber tenido el respeto, porque todas tienen militantes en las asociaciones, de consultarles a sus militantes asociadas (...). Que se hubieran pronunciado con comunicados, con manifiestos, con actos propios, con lo que quisieran apoyando el asunto, pero no que vinieran a nuestras reuniones (...). No mezclar los partidos con el movimiento porque, entonces, ¿a quién reivindicamos? (E10, Tenerife, 10/2017).

Una necesidad constante de clarificar límites que para las que ocupan las intersecciones de la doble militancia adquiere tintes cuasi desgarradores:

... a veces sientes, demasiado a menudo, como que no eres feminista del todo, que no eres feminista de base porque estás dentro de una organización mixta. (...) muy duro, es muy duro, tienes que luchar en un doble frente (E9, Valencia, 09/2017). 


\section{Falta de recursos:}

La valoración del $7 \mathrm{~N}$ como hito suele ir acompañada del reconocimiento de que fue posible a pesar de la congénita falta de recursos del movimiento: "somos capaces, desde la precariedad, de movilizarnos" (E3, Santiago, 07/2017).

En esta carencia de recursos se observan, no obstante, diferencias. Así, desde las islas se señalan unas dificultades añadidas, mientras que la entrevistada más joven expone una situación generacional conjugada con las particularidades de su territorio:

...la gente que tiene mi edad normalmente acaba trabajando fuera (...) quién está acaba trabajando en hostelería o acaba trabajando en cuestiones que es muy difícil tener un fin de semana o que sepas si dentro de un mes vas a poder ir a algún sitio (E13, León, 12/2017).

Unas diferencias que también se establecen entre las feministas que tienen respaldo de las instituciones y las que no, algo que explícitamente reconoce una sindicalista:

...mi viaje estaba pagado por mi sindicato, pero claro, había mujeres que lo tenían que pagar de su bolsillo, o asociaciones de mujeres que no tienen como para pagarse eso (E9, Valencia, 09/2017).

Una diferencia que se convierte en agravio para un feminismo que se percibe autónomo al considerar que las coloca en desventaja cuando se trata de defender posturas en espacios estratégicos:

Somos pobres hasta para...Entonces, las que tienen más recursos son las que están en los sindicatos, o las que están en partidos. Que eso te da un poco de coraje. Que al final, cuando hay un gran debate, es decir, a cuchillo, pues al final quién sobrevive es quien tiene una organización fuerte que responde detrás, y dices jjolín esto es injusto para el movimiento feminista! (E7, Barcelona, 08/2017).

Esta carencia de recursos lleva a explorar límites respecto a lo institucional. Así, en el traslado a Madrid desde los distintos territorios, con frecuencia se recurrió a apoyos procedentes de este ámbito. Para una parte, esto era algo que había que hacer y salió bien:

Ir de Galicia a Madrid no es barato, no todas nos podemos permitir. Entonces, las autoridades ponían unos buses y podíamos facilitar que mujeres que no tenían recursos económicos para desplazarse pudieran ir a coste cero (E3, Santiago, 07/2017).

...supieron estar en una segunda fila, y siempre acompañando, y dando todo su apoyo. Desde apoyo a nivel de prensa, apoyo a nivel económico cuando era necesario, apoyo de transporte. Aquí muchísimos de los autobuses salieron por Intersindical y por Comisiones y por IU y por el PSOE, y perfecto (E8, Valencia, 09/2017). 
Para otras, representa claramente un problema. Consideran que compromete la independencia y que es utilizar recursos públicos que deberían emplearse en atención:

...sabíamos que en aquel momento la financiación que había para igualdad y para violencia de género era insuficiente (...). Una cosa es que la administración te financie un proyecto de educación popular feminista, o unas jornadas o tal, y otra cosa es que te financie la pancarta de una manifestación y tengas que poner el logo de la administración (E10, Tenerife, 10/2017).

\section{Reconocimientos y apoyos institucionales}

Después de la Marcha se produjeron dos situaciones que también tensionaron los límites. La primera fue un premio otorgado por las Juventudes Socialistas a la Plataforma $7 \mathrm{~N}$. Aunque la Plataforma decidió no aceptarlo, entre las que aluden a este suceso hay dos posturas. Una que considera que aceptarlo hubiera sido impropio porque supondría entrar en el juego partidista: "era una manera de instrumentalizar una manifestación para unos fines electorales" (E7, Barcelona, 08/2017). Y otra que no encuentra problema: "yo defendía que cualquier plataforma era buena para hablar de nuestra causa" (E1, Madrid, 06/2017).

La otra situación tiene lugar en Madrid, en la conmemoración del primer aniversario del $7 \mathrm{~N}$. Tras las acciones de calle se desarrolló un acto en el local de un sindicato, un hecho no exento de polémica: "fue algo que estaba fuera de lugar. Hemos estado luchando mucho para ir sin siglas..." (E9, Valencia, 09/2019).

\subsection{La articulación de las agendas}

Los testimonios reflejan claridad en los objetivos del $7 \mathrm{~N}$ respecto a la articulación de agendas. Así, se argumenta la necesidad de que las violencias machistas estén en el imaginario colectivo, en la agenda pública: "hacer de esto un gran problema" (E1, Madrid, 06/2017). Lo que pasa porque la sociedad se identifique con el lenguaje empleado: "el tema de violencias machistas y no violencia de género, creo que es más fácil de entender por la sociedad y, además, hace alusión a violencias que estaban invisibilizadas" (E6, Madrid, 08/2017).

Este impacto en el imaginario colectivo se concibe como una presión necesaria para conseguir que la violencia sea una cuestión de Estado, posibilitando que se traslade al más alto nivel institucional: Congreso, Gobierno, partidos políticos... (agenda formal). Todo ello sobre la base de una agenda feminista común y un análisis de oportunidad política que tiene en cuenta el ciclo electoral, el recorrido de la ley de violencia de género, los instrumentos legales internacionales, así como el momento de auge del feminismo.

Si no hubiera ocurrido esta movilización, no se le habría prestado tanta atención, no se habría hablado de ello en el Congreso de los Diputados y Diputadas, no se habrían adherido los partidos, no habría salido la idea de Pacto de Estado contra la violencia de género. (...) Creo que volvimos a poner la 
violencia de género en la agenda política (E10, Tenerife, 10/2017).

...esos contenidos que te puede parecer que están ahí en un manifiesto, pero esos contenidos han sido la base sobre la que han estado tirando ahora en el Pacto de Estado (...), pone en la agenda política la agenda feminista. Porque además coincidió que había elecciones. (E6, Madrid, 08/2017)

Estas entrevistadas valoran como éxito lo conseguido, aunque no se haya obtenido todo lo que se reclamaba:

Yo no te digo que lo del Pacto de Estado famoso salga bien, pero que se haya puesto el foco mediático y político en el tema es importante para nosotras. Y que los partidos hayan estado con unas comisiones en el Congreso y Senado y que se haya reflexionado, que las Comunidades Autónomas hayan reflexionado sobre el Convenio de Estambul y hayan actualizado sus leyes (...). Yo creo que la enseñanza es que cuando confluimos, influimos (E10, Tenerife, 10/2017).

Es un Pacto, no es la Cuestión de Estado que nosotras planteábamos (...) hemos logrado transmitir la importancia del tema, pero en negativo, no hasta el punto de que sea la prioridad absoluta de todas las instituciones del Estado (E6, Madrid, 08/2017).

Sin embargo, esta idea compartida sobre incidencia muestra sus fisuras cuando se trata de decidir qué hacer tras la Marcha, de actuar yendo más allá de simplemente dejar que la presión social por el éxito de la movilización haga su recorrido:

Los momentos jodidos: el paso de la manifestación a la gestión de las reivindicaciones de la manifestación. (...) Las reivindicaciones no las quieren gestionar y yo creo que eso rompe la cadena. (...) La gente no puede pensar que las manifestaciones no valen para nada, tenemos que ver que gracias a que hay manifestaciones y movilización social hay algo que mejora, algo (E5, Madrid, 08/2017).

La iniciativa de prolongar la acción del 7N mediante la creación de una Plataforma pone en evidencia diferentes posicionamientos. Una de sus partidarias relata el proceso de decisión:

... ¿qué hacemos? ¿tiramos para delante con la fuerza de la movilización o bien, como el objetivo unitario era hacer una gran convocatoria, ya hemos cumplido el objetivo y se deja? Hubo una reunión del 7N exclusivamente para debatir esto. (...) Valencia lo tuvieron muy claro que no querían seguir. En un sector de Madrid tampoco, pero la verdad que el grueso de los territorios que habían permanecido de una forma más activa (...) prácticamente siguen. Después de eso el impulso más grande lo ha tomado Madrid. Yo lo tuve muy claro (...) porque a mí me parece que la fuerza que tuvo la movilización da de sí como para tener esa interlocución política y mover hacia más cosas, hacia logros concretos. Mientras que si tú esa demostración de fuerza la dejas ahí ¿qué has conseguido? (E6, Madrid, 08/2017).

Entre las motivaciones de las partidarias hay mucho de no querer perder lo que se había conseguido, especialmente en lo que compete a la articulación 
territorial que la organización del $7 \mathrm{~N}$ supuso. Algo que justamente resaltan las entrevistadas residentes en los lugares más periféricos: "consolidar la forma $7 \mathrm{~N}$ que nos una a todos los territorios" (E11, Fuerteventura, 10/2017); "nos genera contenido de debate y es continuismo para nosotras" (E12, Alcázar, 10/2017).

Respecto a las posiciones en contra, se pueden identificar dos momentos. Uno inmediatamente después de la Marcha, cuando se debate sobre su constitución, donde se manejan dos argumentos: no prolongar lo que es un día, y volver al territorio.

...era esa fecha, y ya está. Porque repetir una misma acción muchas veces es lo que hace que el movimiento que se construya vaya cada vez a menos, menos, menos, y al final lo que recuerdas es lo que fue (...). Decidimos que habíamos ido a Madrid, lo habíamos dado todo, pero ya está, (...) lo que hay que hacer es volver al territorio y trabajar en el territorio (E8, Valencia, 09/2017).

El otro momento se produce tras la constitución de la Plataforma, con descuelgues motivados por desacuerdos con su funcionamiento. Las argumentaciones apuntan, sobre todo, a la falta de representación: "si no es estatal, representación estatal de todos los territorios, no tiene mucho sentido" (E2, Madrid, 07/2017). Cabe deducir que esta infrarrepresentación pudiera estar relacionada con que el sobresfuerzo que supuso el $7 \mathrm{~N}$ resultaba insostenible. A ello contribuyó el contexto de la Subcomisión para el Pacto de Estado, que forzó a la Plataforma a desplegar una intensa actividad de incidencia política allá donde están las instituciones competentes, en Madrid, y a un ritmo difícil de seguir desde otros territorios y organizaciones. Todo ello condujo a que la Plataforma se fuera percibiendo cada vez más como algo ajeno y centralista:

... yo no puedo estar para mi organización trabajando para la plataforma aquí. Además, tengo mi vida (...). Entonces queda un grupo de mujeres que creo que siguen haciendo un trabajo extraordinario (...). Nos parece desde la periferia que es una cuestión más de las compañeras de Madrid (E3, Santiago, 07/2017).

Así, es fácil deducir que el no estar para formar parte del proceso de toma de decisiones derivara en desconfianzas. Desde ellas, la labor de la Plataforma empezó a ser vista por algunas como algo impropio, casi asimilado a lo institucional y centralista: "que se haya convertido en una Plataforma de Madrid, casi institucional, es lo que decimos algunas" (E9, Valencia, 09/2017).

\section{BREVE CONCLUSIÓN}

Detrás de la imagen unitaria del $7 \mathrm{~N}$ hubo un ingente trabajo colectivo para la confluencia desarrollado a lo largo de casi nueve meses. La clave principal estuvo en hacer compatible la idea de unidad con la de diversidad. Fue un proceso abierto e inclusivo donde la participación permitió sentirse parte y una apropiación colectiva de la idea. Para ello fue necesario construir un marco de 
interpretación lo suficientemente amplio como para diluir las diferencias y realizar el ejercicio de contención que supone no abordar cuestiones que provocarían ruptura. Aquí, Melucci cobra toda su significación.

La unidad actuó como idea-fuerza, un referente materializado en confluencia para la ocasión, construido, inevitablemente, sobre bases difusas y precarias. El "nosotras", como señalaba Melucci, nunca llegó a ser completamente estable ni integrador en virtud de la tensión entre fines, medios y ambiente que le es consustancial. Se asemejó a una foto que focaliza y fija algo que, por su naturaleza, en tanto que movimiento, no puede parar, dejar de mutar y de reaccionar a estímulos, entre ellos, los provenientes de su propia imagen de unidad inmortalizada y convertida, a partir de ahí, en referente épico.

Cabría, por tanto, hablar de una unidad que, en realidad, no existe más allá de coincidencias efímeras e intermitentes, de confluencias, pero que sí existe en tanto que referente útil. Útil para una identidad colectiva que necesita nutrirse de esta idea para no dejar de ser. Y útil para la incidencia política que precisa de una base social amplia para conectar agendas (feminista-pública-formal).

El sobresfuerzo que supone confluir masiva y unitariamente es enorme, no es sostenible. En parte por la naturaleza dinámica de todo movimiento, especialmente del feminista, caracterizado por su gran diversidad, que pudo posar para la foto de la Marcha, y poco más. Luego la inercia de la dispersión se impuso. En ello tuvo mucho que ver la tensión que se produjo entre exigir a las instituciones y el miedo a ser fagocitadas por ellas. Pero también el que la confianza sobre la que se construye esa confluencia disfrazada de unidad requiere de distancias cortas, máxime cuando se trata de gestionar, como señalan McCarthy et al. (1999), uno de los componentes más controvertidos para todo movimiento: la incidencia política sobre unas instituciones, para más inri, del Estado, con todas las suspicacias añadidas hacia el centralismo que ello conlleva, especialmente en un contexto como el español. Y acortar distancias para participar en los procesos de decisión no era ya una opción para un movimiento sostenido casi exclusivamente por el voluntarismo de sus activistas.

El $7 \mathrm{~N}$ fue la primera gran manifestación del feminismo contemporáneo en el Estado español realizada bajo la denominación unitaria de "movimiento feminista". Por muy efímera que resultara ser esa confluencia, evidenció que es algo que se puede lograr desde la diversidad, haciendo que la ficción de unidad parezca tan real y visible como para influir en la sociedad y en las instituciones. En definitiva, el $7 \mathrm{~N}$ es ya un útil referente de unidad para futuras confluencias.

\section{BIBLIOGRAFÍA}

AGUILAR, S. (2019): “¿Son políticamente relevantes los movimientos sociales? una aproximación al caso español”, en Movimientos sociales, acción colectiva y cambio social en perspectiva, España, Betiko, pp. 177-192

AUGUSTÍN, M. (2003): Feminismo: identidad personal y lucha colectiva, Granada, Universidad de Granada 
BORRAZ, M. \& DOMENECH, M. (07/11/2015): "Una marcha histórica y multitudinaria toma la calle contra la violencia machista", Eldiario.es, disponible en: https:// www.eldiario.es/sociedad/feminismo-exigir-violencia-machista-cuestion_1_2391918.html [consulta: 22-09-2020]

COBB, R. W.; ROBB, J. y ROBB, M. H. (1976): “Agenda building as a comparative political process", The American Political Science Review, 70, 1, pp. 126-138

GAGO, V. (2019): La potencia feminista. O el deseo de cambiarlo todo, Madrid, Traficantes de Sueños

GALDÓN, C. (2018a): "La interacción entre los movimientos sociales y el feminismo: Estrategias feministas en la acampada de la puerta del Sol de Madrid", en Hilos violeta. Nuevas propuestas feministas, Madrid, UCM, pp. 229-240

(2018b): "Cosmovisiones feministas en clave generacional. Del movimiento 15M a la huelga feminista del 8M", Encrucijadas, 16, 1602, pp.1-26

GIL, S.L. (2011): Nuevos feminismos. Sentidos comunes en la dispersión, Madrid, Traficantes de Sueños

(2018): "Los feminismos que vienen", en El atlas de las mujeres en el mundo, Madrid, Clave Intelectual, pp. 18-21

LA SEXTA (07/11/2015): "Marcha histórica y masiva en Madrid contra la violencia machista", Noticias La Sexta, disponible en: https://www.youtube.com/ watch?v=AbY_1I53dsY [consulta: 23/09/2020]

MARTÍNEZ, M. (2019): Identidades en proceso. Una propuesta a partir del análisis de las movilizaciones feministas contemporáneas. Madrid: CIS

McCARTHY, J. D., SMITH J. \& ZALD, M. N. (1999): "El acceso a la agenda pública y a la agenda del gobierno: medios de comunicación y sistema electoral", en Movimientos sociales: perspectivas comparadas, Madrid, Istmo, pp. 413-441

MELUCCI, A. (1991). "La acción colectiva como construcción social.”, Estudios Sociológicos, 9, 26, pp. 357-364

(1994): “QQué hay de nuevo en los nuevos movimientos sociales?”, en Los nuevos movimientos sociales, Madrid, CIS, pp. 119-150

(1999): "Teoría de la acción colectiva", en Acción colectiva, vida cotidiana y democracia, México, El Colegio de México, pp. 25-54

MUELLER, C. (1994): "Identidades colectivas y redes de conflicto: El origen del movimiento feminista en los estados unidos, 1960-1970", en Los nuevos movimientos sociales, Madrid, CIS, pp. 287-320

ROVIRA, G. (2018) "El devenir feminista en la acción colectiva: las redes digitales y la política de prefiguración de las multitudes conectadas", Teknokultura, 15(2), pp. 223-240 